\title{
Synthesis and Characterization of a Novel Mesoporous Mn - Organophosphate Molecular Sieve
}

\author{
Venkatathri Narayanan ${ }^{\mathrm{a} *}$, Santhanaraj Daniel ${ }^{\mathrm{b}}$, Shanthi Kannan ${ }^{\mathrm{b}}$ \\ ${ }^{a}$ Department of Chemistry, National Institute of Technology, \\ Warangal 506 004, Andhra Pradesh, India. \\ ${ }^{\mathrm{b}}$ Department of Chemistry, Anna University, \\ Chennai 600 025, Tamil Nadu, India.
}

Received: March 20, 2009; Revised: August 5, 2009

\begin{abstract}
A novel mesoporous $\mathrm{Mn}$ - organophosphate was synthesized for the first time. It is characterized by several physicochemical techniques. Small angle X-ray diffraction analysis shows the first peak in $2.5^{\circ}$ with $39 \mathrm{~A}^{\circ}$ pore width. Elemental analysis shows that the composition is $\left[\left(\mathrm{C}_{12} \mathrm{H}_{23} \mathrm{~N}\right)_{3} \mathrm{PO}\right]^{40} \mathrm{Mn}$. Scanning electron microscopic picture shows the flag morphology with $1-15 \mu \mathrm{m}$ particle size. Thermogravimetry/Differentaial thermal analysis shows almost $80 \%$ exothermic weight loss. Nitrogen adsorption isotherm shows type III with $300 \mathrm{~m}^{2} / \mathrm{g}$ BET surface area. Fourier transform Infrared spectroscopic analysis shows that the framework vibrations are comparable to other well known silica mesoporous materials. Electron spin resonance spectroscopic analysis shows the absence of hyperfine splitting indicates the presence of $\mathrm{Mn}^{3+}$ species. Ultraviolet - visible spectroscopic analysis shows that most of the Mn is in tetrahedral co-ordination beside small square pyramidal species. A plausible synthesis mechanism also proposed.
\end{abstract}

Keywords: mesoporous, $M n$ - organophosphate, characterization

\section{Introduction}

Mesoporous materials are popular due to their high surface area and unique morphology ${ }^{1-10}$. The known variety of mesoporous materials are few, namely MCM-41, MCM-48 and SBA-15. The main draw back in these materials synthesis is their prolonged crystallization, low yield and high cost of reagents. There are several efforts were made in this direction to solve these problems. Recently, organophosphates were synthesized and reported ${ }^{11-13}$ to have properties similar to zeolites. Compared to zeolites, they are prepared in short time, low cost and high yield. However mesoporous organophosphate molecular sieves are not reported so far. Beside pure organophosphate molecular sieves are not suitable for redox type catalyzed reactions. To prepare redox catalyst, a metal oxide has to be either supported or incorporated inside the structure. As the supported metal oxides is leachable to liquid phase oxidation reactions. It is necessary to prepare metal incorporated molecular sieves. There are several metal incorporated ${ }^{14-38}$ molecular sieves are reported in literature. But there is less studies on Mn containing molecular sieves ${ }^{12}$. In the present study, we have synthesized $\mathrm{Mn}$ - containing mesoporous organophosphate for the first time and it is characterized in detail.

\section{Experimental}

In a typical procedure to synthesis mesoporous Mn-organophosphate, the manganese acetate $(\mathrm{P} / \mathrm{Mn}=40$, Aldrich, USA) was dissolved in othophosphoric acid ( $85 \%$, s.d.fine, India). To this mixture, 1:4 molar ratio of Dodecylamine (98\%, Aldrich, U.S.A) was added and stirred well. A pink solid was resulted. The ground solid was dried at $80{ }^{\circ} \mathrm{C}$ for $12 \mathrm{~h}$. The resulting solid was subjected to following physicochemical characterizations.

The above samples were analyzed for qualitative phase identification by small angle X-ray powder diffraction (Rigaku, Model D/MAX III VC, Japan, Ni filtered $\mathrm{Cu}-\mathrm{K} \alpha$ radia- tion, $\lambda=1.5404 \AA$ ). The morphology of the organophosphate was investigated using a scanning electron microscope (JEOL ${ }^{\circledR}$, JSM 5200). Transmission electron micrographs (TEM) of the samples were scanned on a JEOL JSM-2000EX electron microscope operated at $200 \mathrm{kV}$. Simultaneous Thermogravimetry/Differential thermal analysis of the crystalline phases was performed on an automatic derivatograph (Setaram TG-DTA 92). The adsorption and desorption measurements were carried out using an Autosorb -1 instrument. The Fourier transform infrared spectroscopy was recorded in the diffuse reflectance mode using a 300:1 ratio sample in $\mathrm{KBr}$ (Nicolet 60SXB). Electron spin resonance spectra of the as-synthesized Mn - organophosphate was obtained using Bruker ER 200D spectrometer. The spectra were recorded at room temperature as well as at liquid nitrogen temperature. The spectra were recorded (with a mid range of $4000 \mathrm{G}$ ) in the scan range of 0 to 8000 gauss and magnetic field strength was $9.74 \mathrm{GHz}$. The Ultraviolet - visible diffuse reflectance spectra were recorded using a Pye Unichem (SP-8-100) spectrometer in the $200-800 \mathrm{~nm}$ regions.

\section{Results and Discussion}

The X-ray diffraction pattern of the $\mathrm{Mn}$ - organophosphate (Figure 1) shows the peaks at $2.6(54 \%), 3.8(46 \%), 5.3(29 \%)$, $7.7(100 \%)$ and $8.0(71 \%)$. The appearance of peaks at low angle region in equal distance shows that the Mn-organophosphate is mesoporous lamellar type. The X-ray diffraction pattern is stable up to $200{ }^{\circ} \mathrm{C}$. From the interplanar distance (d) analysis, the pore openings are calculated as $3.9 \mathrm{~nm}\left(39 \mathrm{~A}^{\mathrm{o}}\right)^{[39]}$. Elemental analysis shows that the $\mathrm{Mn}$ - organophosphate has composition, $\left[\left(\mathrm{CH}_{3}-\left(\mathrm{CH}_{2}\right)_{11} \mathrm{NH}\right)_{3} \mathrm{PO}\right]^{40} \mathrm{Mn}$.

Scanning electron micrograph of mesoporous Mn - organophosphate (Figure 2a) shows that the particle size is not uniform $(1-15 \mu \mathrm{m})$, 


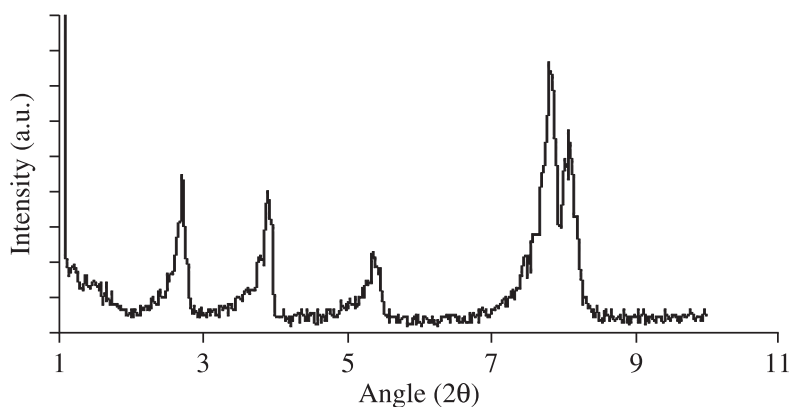

Figure 1. Low angle X-ray diffraction pattern of mesoporous Mn - organophosphate molecular sieve.

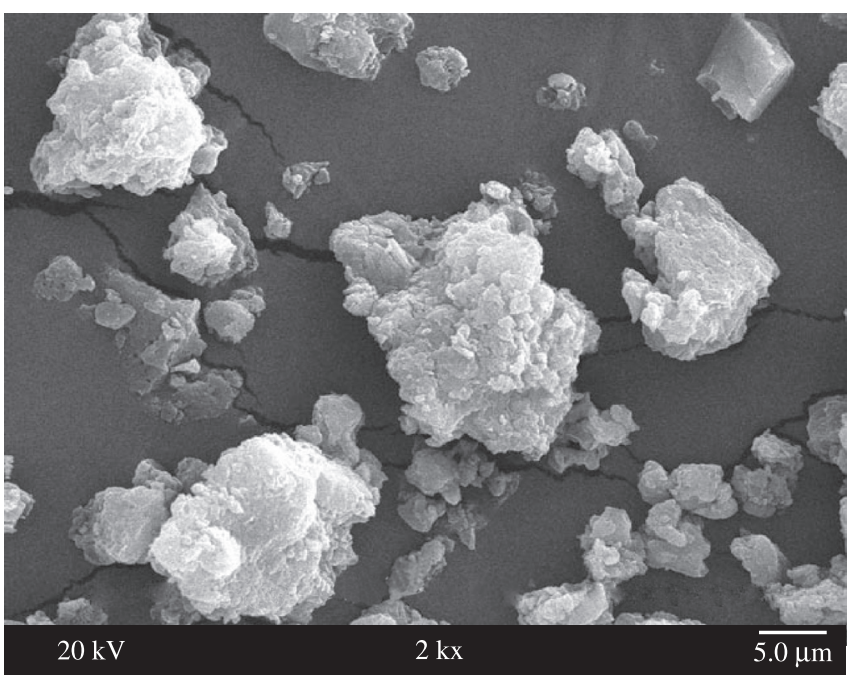

(a)

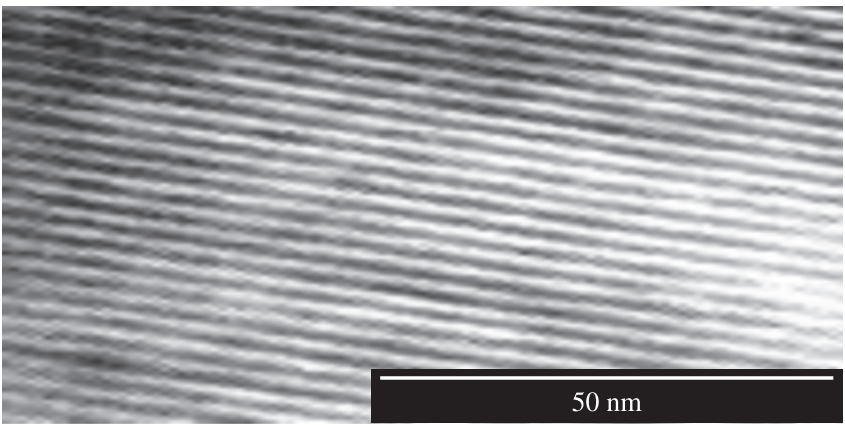

(b)

Figure 2. a) Scanning electron micrograph and b) Transmission electron micrograph of mesoporous $\mathrm{Mn}$ - organophosphate molecular sieve.

however the shape is almost similar (flag shape). It is not soluble in aqueous or non-aqueous media. Presence of manganese plays a major role in it. Transmission electron micrograph of mesoporous $\mathrm{Mn}$ - organophosphate (Figure $2 \mathrm{~b}$ ) shows a regular fringe. The well define fringe also shows its crystallinity.

The Thermogravimetry/Differential thermal analysis of mesoporous $\mathrm{Mn}$ - organophosphate (Figure 3) losses the total weight exothermically at $25-750{ }^{\circ} \mathrm{C}(80 \%)$. Unlike pure organophosphate (Figure is not shown) the Mn containing organophosphate losses the total weight at lower temperature. It may be due to the metal catalyses the oxidative decomposition of organics.

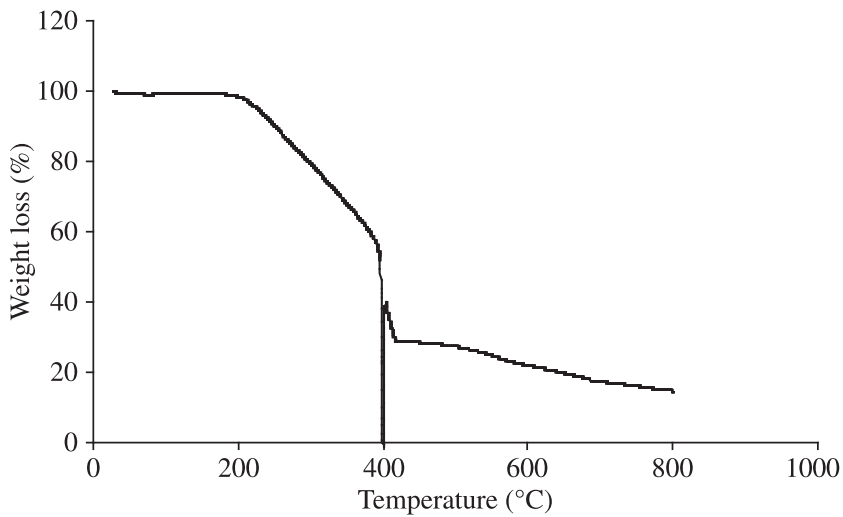

(a)

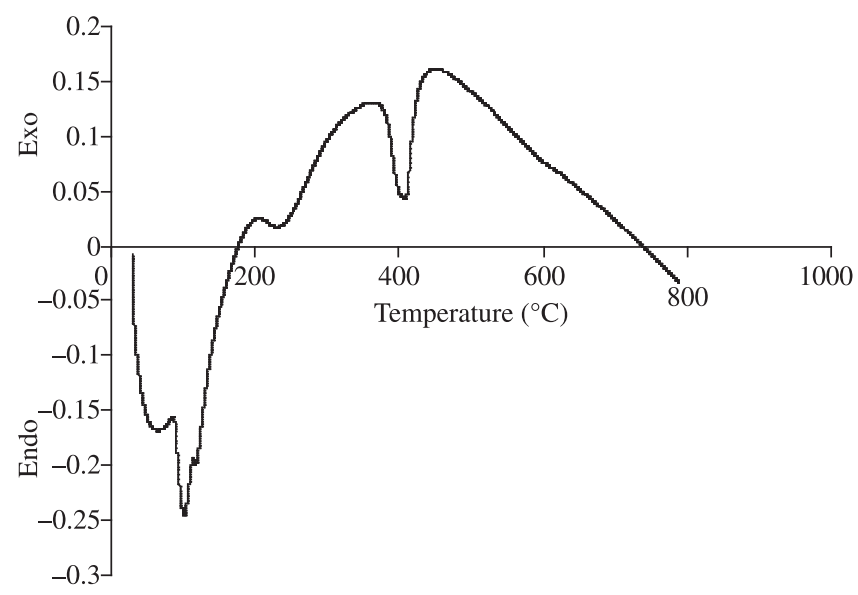

(b)

Figure 3. Thermogravimetry (a)/Differential thermal analysis (b) curves of mesoporous $\mathrm{Mn}$ - organophosphate molecular sieve.

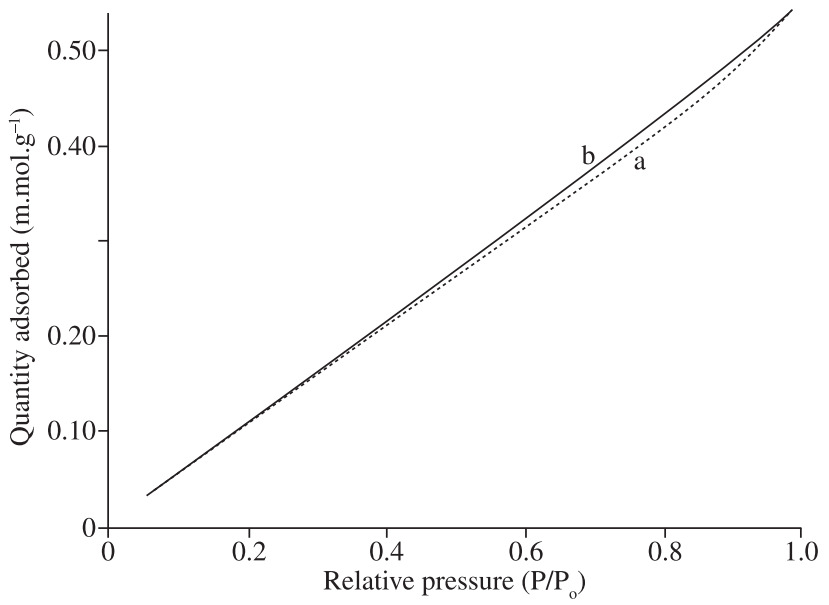

Figure 4. Nitrogen adsorption isotherm curves of mesoporous Mn - organophosphate molecular sieve.

The Nitrogen adsorption isotherms of $\mathrm{Mn}$ - organophosphate is of type III ${ }^{40}$ (Figure 4). The surface area is $300 \mathrm{~m}^{2} / \mathrm{g}$ and pore width is $40 \mathrm{~A}^{\circ}$. These results were taken after the materials were activated at $100{ }^{\circ} \mathrm{C}$ before measurement. If the material was activated at room temperature, no adsorption was taken place. Normally molecular sieves are activated at $400{ }^{\circ} \mathrm{C}$ in vacuum to remove the volatile impurities. The X-ray diffraction pattern of mesoporous Mn-organophosphate 


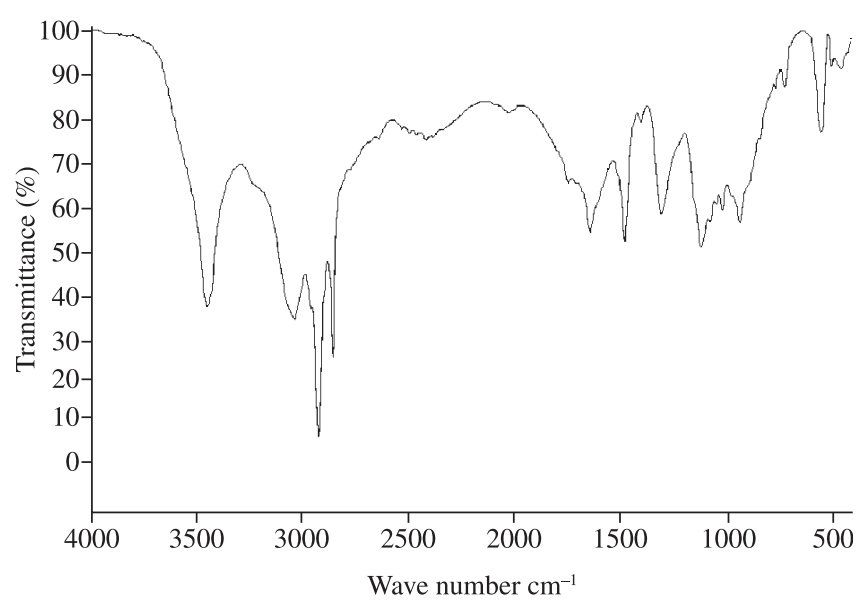

Figure 5. Fourier transform infrared spectrum of mesoporous Mn - organophosphate molecular sieve.

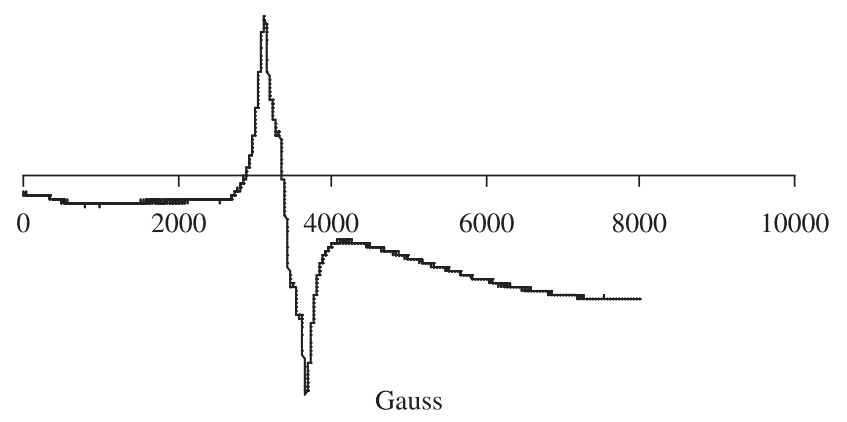

Figure 6. Electron spin resonance spectroscopic analysis of mesoporous $\mathrm{Mn}$ - organophosphate molecular sieve.

is reproducible even after its thermal treatment up to $200{ }^{\circ} \mathrm{C}$. As we know, the X-ray diffraction reproducibility is essential for better nitrogen adsorption, so we have activated the sample under vacuum at $100{ }^{\circ} \mathrm{C}$.

The Fourier transform infrared spectrum of as-synthesized mesoporous $\mathrm{Mn}$ - organophosphate shows (Figure 5) a similar spectrum to other mesoporous molecular sieves. However there are slight changes in intensities. There was peak observed for Mn-O-P vibrations at $960 \mathrm{~cm}^{-1}$ band. Electron spin resonance spectrum of mesoporous Mn- organophosphate shows (Figure 6) a single peak for $\mathrm{Mn}^{3+}$ oxidation state. It is noted that the $\mathrm{Mn}^{2+}$ is having six hyperfine splitting in ESR $(I=5 / 2)^{41}$. At liquid nitrogen temperature the peaks intensity is four times higher than the room temperature pattern. Further, even though the source manganese is in $\mathrm{Mn}^{2+}$ state, when react with acid it is getting oxidized to $\mathrm{Mn}^{3+}$. Besides for a stable framework, Manganese should be in $\mathrm{Mn}^{3+}$. A week $\mathrm{Mn}^{2+}$ hyperfine splitting was also noticed.

Figure 7 shows the Ultraviolet - visible spectra of mesoporous $\mathrm{Mn}$ - organophosphate. There is a small peak at $300 \mathrm{~nm}$ is due to the presence of tetrahedrally co-ordinated $\mathrm{Mn}$ or $\mathrm{P}$ species $^{41}$. Another peak at $415 \mathrm{~nm}$ is due to square pyramidal species. In Mn - organophosphate, only the tetrahedrally co-ordinated manganese is expected. However due to partial hydration, the square pyramidal species is appeared.

Scheme 1 shows a plausible mechanism for mesoporous Mn-organophosphate synthesis. Orthophosphoric acid has three hydroxyl groups. This three hydroxyl can be easily reacting with

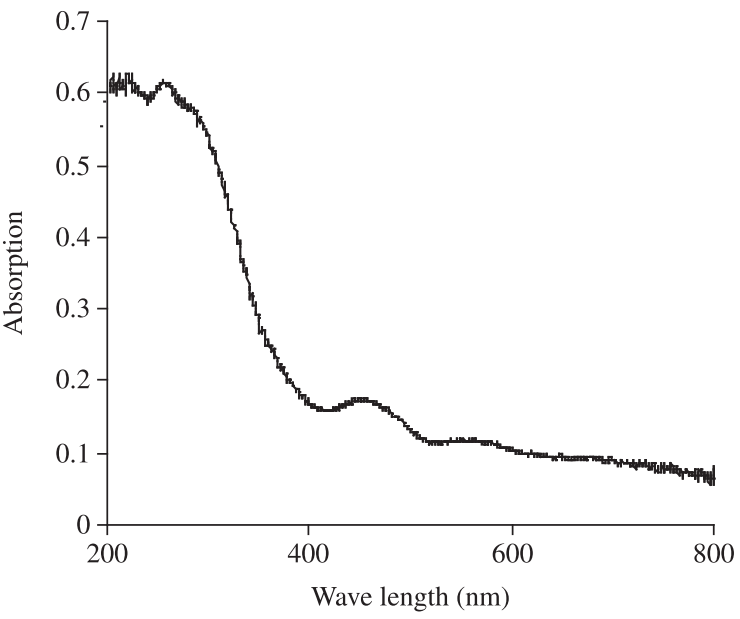

Figure 7. Ultraviolet-visible spectroscopic analysis of mesoporous Mn organophosphate molecular sieve.

$$
\begin{array}{lc}
3 \mathrm{CH}_{3}-\left(\mathrm{CH}_{2}\right)_{11}-\mathrm{NH}_{2}+\mathrm{P}^{5+} \mathrm{O}(\mathrm{OH})_{3} \rightarrow\left[\left(\mathrm{Mn}^{3+}(\mathrm{R}-\mathrm{N})(\mathrm{R}-\mathrm{N}) \mathrm{P}^{5+}(\mathrm{O})(\mathrm{N}-\mathrm{R})\right]_{\mathrm{n}-}\right. \\
(\mathrm{n} \text {-dodecylamine) (orthophosphoric acid) } & \text { Mn-organophosphate } \\
+\mathrm{Mn}^{2+}(\mathrm{ac})_{2} & \left(\mathrm{R}=\mathrm{CH}_{3}-\left(\mathrm{CH}_{2}\right)_{11-}\right) \\
\text { (Manganese acetate) } &
\end{array}
$$

Scheme 1. A plausible mechanism for mesoporous $\mathrm{Mn}$ - organophosphate molecular sieve synthesis.

three amine group. Being a Lewis acid, Mn is reacted with amine (Lewis base). The structural stoichiometry prevents manganese phosphate formation. The similarity of oxygen with nitrogen creates organophosphate structure similar to zeolites. The need for two hydrogen in organic amine supports this proposal. The organophosphate structure is neutral by presence of alternate $\mathrm{P}^{5+}$ and $\mathrm{P}^{3+}$ ions. The $\mathrm{Mn}^{3+}$ ions replace $\mathrm{P}^{3+}$ species to form stoichiometric structure.

\section{Conclusions}

A novel mesoporous $\mathrm{Mn}$ - organophosphate was synthesized for the first time. It is characterized by several physicochemical techniques. Small angle X-ray diffraction analysis shows the first peak at $2.5^{\circ}$ for mesoporosity Elemental analysis shows that the composition is $\left[\left(\mathrm{C}_{12} \mathrm{H}_{23} \mathrm{~N}\right)_{3} \mathrm{PO}\right]^{[40]} \mathrm{Mn}$. Scanning electron microscopic picture shows the flag morphology with $1-15 \mu \mathrm{m}$ particle size. Thermogravimetry/ Differentaial thermal analysis shows almost $80 \%$ exothermic weight loss. Nitrogen adsorption isotherm shows it is of type III with $300 \mathrm{~m}^{2} \cdot \mathrm{g}^{-1}$. surface area. Fourier transform Infrared spectroscopic analysis shows that the framework vibrations are comparable to other well known silica mesoporous materials. Electron spin resonance spectroscopic analysis shows the absence of hyperfine splitting indicates the presence of $\mathrm{Mn}^{3+}$ species. Ultraviolet - visible spectroscopic analysis shows the most of $\mathrm{Mn}$ is in tetrahedral co-ordination beside small square pyramidal species. A plausible mechanism of the reaction was also proposed.

\section{Acknowledgements}

One of the authors N.V thanks The Head, Department of Chemistry, National Institute of Technology, Warangal 506 004, Andhra Pradesh, India for constant encouragement through out the work. 


\section{References}

1. Ying JY, Mehnert CP and Wong MS. Synthesis and applications of supramolecular-templated mesoporous materials. Angewandte Chemie International Edition. 1999; 38(1-2):56-77.

2. Lin HP and Mou CY. Tubules-within-a-tubule" hierarchical order of mesoporous molecular sieves in MCM- 41. Science. 1996; 273(2):765-768.

3. Lin HP, Cheng S and Mou CY. Mesoporous molecular sieves MCM41 with a hollowTubular morpology. Chemistry of Materials. 1998; 10(2):581-589.

4. Yang H, Coombs N and Ozin GA. Morphogenesis of shapes and surface patterns in mesoporous silica. Nature. 1997; 386(1):692-695.

5. Yang SM, Sokolov I, Coombs N, Kresge CT and Ozin GA. Formation of Hollow helicoids in Mesoporous silica: supramolecular origami. Advanced Materials. 1999; 11(17):1427-1431.

6. Han S, Hou W, Dang W, Xu J, Hu J and Li D. Synthesis of rod-like mesoporous silica using mixed surfactants of cetyltrimethylammonium bromide and cetyltrimethylammonium chloride as templates. Materials Letters. 2003; 57(29):4520-4524.

7. Han S, Hou W, Yan X, Li Z, Zhang P and Li D. Effect of Pentanol on Morphologies and Pore structure of Mesoporous silica. Langmuir. 2003; 19(10):4269-4271.

8. Han S, Xu J, Hou W, Yu X and Wang Y. Synthesis of High quality MCM-48 Mesoporous silica using Gemini surfactant dimethylene1-2-bis(dodecyldimethyl - ammonium bromide). Journal of Physical Chemistry B. 2004; 108(39):15043-15048.

9. Fan W and Gao. L. Synthesis of silica hollow spheres assisted by ultrasound. Journal of Colloid and Interface Science. 2006; 297(1):157-160

10. Cochran JK. Ceramic hollow spheres and their applications. Current Opinion in Solid State \& Materials Science. 1998; 3(5):474-479.

11. Venkatathri N. Synthesis, characterization and catalytic properties of a novel organophosphate molecular sieve from n-propylamine. Reaction Kinetics and Catalysis Letters. 2008; 95(1):53-58.

12. Venkatathri N, Santhanaraj D and Shanthi K. Synthesis, characterization and catalytic properties of a novel Mn - organophosphate having MFI topology. Bulletin of the Catalysis Society of India. 2008; 7(1):97-106.

13. Venkatathri N. Synthesis and characterization of a novel organophosphate analogues to zeolite ZSM-5. Bulletin of the Catalysis Society of India 2006; 5(1):146-155.

14. Ulakappan $\mathrm{N}$ and Krishnasamy V. Titanium substitution in silicon free molecular sieves: anatase free TAPO -5 and TAPO -11 synthesis and characterizaton of hydroxylation of phenol. Journal of the Chemical Society, Chemical Communications. 1995; 3(1):373-374.

15. Zahedi-Niaki MH, Joshi PN and Kaliaguine S. Synthesis and characterization of a novel titanium aluminophosphate molecular sieve with ATS structure: TAPO-36. Journal of the Chemical Society, Chemical Communications. 1996; 1(1):47-48.

16. Tuel A and Ben-Taarit Y. Synthesis and catalytic properties of titanium substituted Silico aluminophosphate TAPSO-5. Journal of the Chemical Society, Chemical Communications. 1994; 14(1):1667-1668.

17. Venkatathri N, Hegde SG and Sivasanker S. Synthesis and characterization of a novel vanadium analogue of AlPO-31. Journal of the Chemical Society, Chemical Communications. 1995; 2(1):151-152.

18. Rigutto MS and Van Bekkum H. Vanadium site in VAPO-5: Characterization and catalytic properties in liquid - phase alkene epoxidation and benzylic oxidation. Journal of Molecular Catalysis 1993; 81(1):77-98.

19. Montes C, Davis ME, Murray B and Narayana M. Isolated redox centers within microporous environments. 2. Vanadium containing aluminophosphate molecular sieve five. Journal of Physical Chemistry. 1990; 94(16):6431-6435.

20. Jhung SH, Uh YS and Chon H. Synthesis and characterization of the vanadium incorporated molecular sieve VAPO-5. Applied Catalysis. 1990; 62(1):61-72.
21. Weckhuysen BM and Schoonheydt RA. Synthesis and chemistry of chromium in CrAPO-5 molecular sieves. Zeolites. 1994; 14(5):360366.

22. Eswaramoorthy M, Jebarathina MNJ, Ulagappan N and Krishnasamy V. Chromium substituted AlPO-11: Synthesis, characterization and its applications in oxidations reactions. Catalysis Letters. 1996; 38(34):143-147.

23. Chen JD, Lempers HEB and Sheldon RA. Synthesis, characterization and catalytic oxidation of alcohols with chromium substituted aluminophosphates. Journal of the Chemical Society, Faraday Transactions. 1996; 92(10):1807-1814.

24. Chen JD, Haanepen MJ, Van Hooff JHC and Sheldon RA. CrAPO catalyzed oxidations of alkylaromatics and alcohols with TBHP in the liquid phase (redox molecular sieves part 8). Studies in Surface Science and Catalysis. 1994; 84(2):973-978.

25. Rajic N, Stojakovic D and Kaucic V. Formation of AlPO-15 and CoAPO-15 in the presence of hexamethylenetetramine. Zeolites. 1990; 10(8):802-805.

26. Duke CVA, Hill SJ and Williams CD. Synthesis of MnAPO-20, CoAPO-20, NiAPO-20 and CuAPO-20 using tetrahedral tetrahalometallates. Zeolites. 1995; 15(5):413-420.

27. Tapp NJ, Milestone NB and Wright LJ. Substitution of divalent cobalt into aluminophosphate molecular sieves. Journal of the Chemical Society, Chemical Communications. 1985; (1):1801-1802.

28. Kraushaar-Czarnetzki B, Hoogervorst WGM, Andrea RR, Eemels CA and Stork WHJ. Characterization of $\mathrm{Co}^{\mathrm{II}}$ and $\mathrm{Co}^{\mathrm{III}}$ in CoAPO molecular sieves. Journal of the Chemical Society, Faraday Transactions. 1991; 87(6):891-896.

29. Lohse U, Bertram R, Jancke K, Kurzawski I, Parlitz B and Loffler E. Acidity of aluminophosphate structures. Part2 - Incorporaton of cobalt in to CHA and AFI by microwave synthesis. Journal of the Chemical Society, Faraday Transactions. 1995; 91(1):1163-1172.

30. Batista J, Kaucic V, Rajic N and Stojakovic D. On the formation of CoAPSO-44. Zeolites. 1992; 12(8):925-928.

31. Shiralkar VP, Salddarriaga CH, Perez JO, Clearfield A, Chen M and Anthony RG. Synthesis and characterization of CoAPO-5 a cobalt containing AlPO-5 molecular sieves. Zeolites. 1989; 9(6):474-482.

32. Montes C, Davis ME, Murray B and Narayana M. Isolated redox centers within microporous environments. 1. Cobalt containing aluminophosphate molecular sieve five. Journal of Physical Chemistry. 1990; 94(16):6425-6430.

33. Yokomori Y and Kawachi Y. Synthesis of large single crystals of CoAPO-5 molecular sieves. Zeolites. 1995; 15(7):637-639.

34. Wilson ST and Flanigen EM. Synthesis and characterization of metal aluminophosphate molecular sieves. In: Occelli ML and Robson HE. (Eds.). Zeolite synthesis. Washington: American Chemical Society; 1989. p. 329- 345. (ACS Symposium Series, vol. 398).

35. Flanigen EM, Patton RL and Wilson ST. Innovation in Zeolite Materials Science. Amsterdam: Elsevier; 1988. p.13-17.

36. Bennett JM and Marcus BK. Innovation in Zeolite Materials Science. Amsterdam: Elsevier; 1988. p. 269-275.

37. Zabukovec N, Golic N, Fajdiga P and Kaucic V. Synthesis and structure of a new cobalt containing aluminophosphate. Zeolites. 1995; 15(2):104-110.

38. Akolekar DB. Investigations on the CoAPO-36 molecular sieve. Catalysis Letters 1994; 228(2-4):249-262.

39. Das DP, Parida KM and Mishra BK. A study on the structural properties of mesoporous silica spheres. Materials Letters 2007; 61(18):3942-3945.

40. Sivasanker B. Engineering chemistry. New Delhi: Tata McGraw-Hill; 2008. p. 147-150.

41. Sinha AK. Preparation, characterization and catalytic properties of silico aluminophosphates. [PhD thesis]. Pune: University of Pune; 1999. 